\title{
ASSESSING MONETARY POLICY EFFECTS USING DAILY FED FUNDS FUTURES
} CONTRACTS

\author{
James D. Hamilton \\ Working Paper 13569 \\ http://www.nber.org/papers/w13569
}

\section{NATIONAL BUREAU OF ECONOMIC RESEARCH}

1050 Massachusetts Avenue

Cambridge, MA 02138

November 2007

The views expressed herein are those of the author(s) and do not necessarily reflect the views of the National Bureau of Economic Research.

(C) 2007 by James D. Hamilton. All rights reserved. Short sections of text, not to exceed two paragraphs, may be quoted without explicit permission provided that full credit, including $(\subset$ notice, is given to the source. 


\title{
Assessing Monetary Policy Effects Using Daily Fed Funds Futures Contracts
}

James D. Hamilton

NBER Working Paper No. 13569

November 2007

JEL No. E5

\begin{abstract}
$\underline{\text { ABSTRACT }}$
This paper develops a generalization of the formulas proposed by Kuttner (2001) and others for purposes of measuring the effects of a change in the fed funds target on Treasury yields of different maturities. The generalization avoids the need to condition on the date of the target change and allows for deviations of the effective fed funds rate from the target as well as gradual learning by market participants about the target. The paper shows that parameters estimated solely on the basis of the behavior of the fed funds and fed funds futures can account for the broad calendar regularities in the relation between fed funds futures and Treasury yields of different maturities. Although the methods are new, the conclusion is quite similar to that reported by earlier researchers-- changes in the fed funds target seem to be associated with quite large changes in Treasury yields, even for maturities up to ten years.
\end{abstract}

\author{
James D. Hamilton \\ Department of Economics, 0508 \\ University of California, San Diego \\ 9500 Gilman Drive \\ La Jolla, CA 92093-0508 \\ and NBER \\ jhamilton@ucsd.edu
}




\section{Introduction.}

Economists continue to debate how much of an effect monetary policy has on the economy. But one of the more robust empirical results is the observation that changes in the target that the Federal Reserve sets for the overnight fed funds rate have been associated historically with large changes in other interest rates, even for the longest maturities. This paper contributes to the extensive literature that tries to measure the magnitude of this effect.

One of the first efforts along these lines was by Cook and Hahn (1989), who looked at how yields on Treasury securities of different maturities changed on the days when the Federal Reserve changed its target for the fed funds rate. Let $i_{s, d}$ denote the interest rate (in basis points) on a Treasury bill or Treasury bond of constant maturity $s$ months as quoted on some business day $d$, and let $\xi_{d}$ denote the target for the fed funds rate as determined by the Federal Reserve for that day. Using just those days between September 1974 and September 1979 on which there was a change in the target, Cook and Hahn estimated the following regression by OLS:

$$
i_{s, d}-i_{s, d-1}=\alpha_{s}+\lambda_{s}\left(\xi_{d}-\xi_{d-1}\right)+u_{s d}
$$

Their estimates of $\lambda_{s}$ are reported in the first column of Table 1 for securities of several different maturities. These estimates suggest that when the Fed raises the overnight rate by 100 basis points, short-term Treasury yields go up by over 50 basis points and there is a statistically significant effect even on 10-year yields.

Subsequent researchers found that the magnitude of the estimated coefficients for $\lambda_{s}$ were significantly smaller when later data sets were used. For example, column 2 of Table 1 
reports Kuttner's (2001) results when the Cook-Hahn regression (1) was re-estimated using data from June 1989 to February 2000; see also Nilsen (1998).

However, Kuttner (2001) also identified some conceptual problems with regression (1). For one thing, the market may have anticipated much of the change in the target $\xi_{d}$ that occurred on day $d$ many days earlier, in which case those expectations would have already been incorporated into $i_{s, d-1}$. In the limiting case when the change was perfectly anticipated, one would not expect any change in $i_{s, d}$ to be observed on the day of the target change. To isolate the unanticipated component of the target change, Kuttner used $f_{d}$, the interest rate implied by the spot-month fed funds contract on day $d$. These contracts are settled on the basis of what the average effective fed funds rate turns out to be for the entire month containing day $d$. Since much of the month may already be over by day $d$, a target change on day $d$ will only have a fractional effect on the monthly average. Kuttner proposed the following formula to identify the unanticipated component of the target change on day $d$,

$$
\tilde{\xi}_{d}^{u}=\left(\frac{N_{d}}{N_{d}-t_{d}+1}\right)\left(f_{d}-f_{d-1}\right),
$$

where $N_{d}$ is the number of calendar days associated with the month in which day $d$ occurs and $t_{d}$ is the calendar day-of-the-month associated with day $d$. Kuttner then replaced (1) with the regression

$$
i_{s, d}-i_{s, d-1}=\alpha_{s}+\gamma_{s}\left(\xi_{d}-\xi_{d-1}-\tilde{\xi}_{d}^{u}\right)+\lambda_{s} \tilde{\xi}_{d}^{u}+u_{s d}
$$

with additional modifications if $d$ were the first day or one of the last three days of a month. Kuttner found that the $\gamma_{s}$ were essentially zero, meaning that target changes that were 
anticipated in advance have no effect on other interest rates. Kuttner's estimates of $\lambda_{s}$, the effects of unanticipated target changes, are reported in column 3 of Table 1, and turn out to be a bit larger than the original Cook-Hahn estimates.

Poole and Rasche (2000) proposed to sidestep the issues associated with a mid-month target change by using not the spot-month contract on day $d$ but instead the one-monthahead contract, that is, the interest rate implied by a contract purchased on day $d$ for settlement based on the average fed funds rate prevailing in the following month, denoted $f_{d}^{1}$. They then replaced the expression in (2) with

$$
\tilde{\xi}_{d}^{u}=f_{d}^{1}-f_{d-1}^{1} .
$$

Their estimates for $\lambda_{s}$ using this formulation turned out to be similar to Kuttner's, and are reported in the fourth column of Table 1.

However, mid-month target changes remain an issue for the Poole-Rasche estimates, because there is always the possibility of a second (or even a third) change in the target some time after day $d$ and before the end of the following month; indeed this turned out to be the case for about half of the target changes observed between 1988 and 2006. Gürkaynak, Sack, and Swanson (2007) developed an analog to Kuttner's formula (2) based on the date of the next target change that followed after the one implemented on day $d$; see also Gürkaynak (2005).

Another potential drawback to either (2) or (4) was raised by Poole, Rasche and Thornton (2002). These authors noted that, particularly prior to 1994, market participants may not have been perfectly aware of the target change even at the end of day $d$, in which 
case these formulas would include a measurement error that would bias the coefficients downward. Poole, Rasche and Thornton developed corrections for the estimates to allow for this measurement error.

A related issue is that the series for $\xi_{d}$, the actual target change, is itself subject to measurement error, as indeed Kuttner (2001) and Poole, Rasche and Thornton (2002) used slightly different series. Learning about the target change presumably also began well before day $d$. For both reasons, one would think that data both before and after day $d$ should typically be used. In this paper I develop a generalization of the Kuttner (2001) and Poole, Rasche, and Thornton (2002) adjustments for purposes of estimating the parameter $\lambda_{s}$. The basic idea is to suppose that there exists some day within the month at which the target may have been changed, but to choose deliberately not to condition on this date for purposes of forming an econometric estimate. The paper also generalizes the earlier approaches by explicitly modeling the difference between the effective fed funds rate and the actual target.

I begin in Section 2 with an examination of the relation between the target rate chosen by the Fed and the actual effective fed funds rate. Section 3 develops a simple statistical description of how these deviations, along with the process of learning by the market about what the fed funds target is going to be for this month, would determine the volatility of the spot-month futures rates. I show in Section 4 how the parameters estimated from the behavior of the effective fed funds rate and the spot-month futures rate can be used to predict calendar regularities in the estimated values for a generalization of the coefficient $\lambda_{s}$ 
above. Section 5 finds such calendar regularities largely borne out in the observed relation between Treasury rates and daily changes in the spot-month futures rate, and develops new estimates of this parameter. Although the method and data set are rather different from the earlier researchers, my estimates in fact turn out to be quite similar to those originally found by Kuttner (2001) and Poole and Rasche (2000).

\section{The effective and target fed funds rate.}

In this paper I will be indexing time in two different ways, using calendar days $t$ for developing theoretical formulas and business days $d$ to apply these ideas to actual data. The theoretical formulas will be developed for a typical month consisting of $N$ calendar days indexed by $t=1,2, \ldots, N$, whereas the data set will consist of those days $d=1,2, \ldots, D$ for which I have data on both Treasury interest rates and fed funds futures rates; $d=1$ corresponds to Oct 3 , 1988 and $d=D=4552$ corresponds to Dec 29, 2006. The empirical sample for all estimates reported in this paper also excludes the volatile data from September 13 to September 30, 2001.

The effective fed funds rate for calendar day $t$, denoted $r_{t}$, is a volume-weighted average of all overnight interbank loans of Federal Reserve deposits for that day. All numbers in this paper will be reported in basis points, so that, for example, a $5.25 \%$ interest rate would correspond to a value of $r_{t}=525$. Since October 1988, the Chicago Board of Trade has

offered futures contracts whose settlement is based on the average value for the effective fed funds rate over all the calendar days of the month (with Friday rates, for example, also 
imputed to Saturday and Sunday). For a month that contains $N$ calendar days, settlement of these futures contracts would be based on the value of

$$
S=N^{-1} \sum_{t=1}^{N} r_{t} .
$$

The terms of a given fed funds futures contract can be translated ${ }^{1}$ into an interest rate $f_{t}$ such that, if $S$ (which is not known at day $t$ but will become known by the end of the month) turns out to be bigger than $f_{t}$, the buyer of the contract has to compensate the seller by a certain amount for every basis point by which $S$ exceeds $f_{t}$. If the marginal market participant were risk neutral, it would be the case that

$$
f_{t}=E_{t}(S)
$$

where $E_{t}($.$) denotes an expectation formed on the basis of information available to the market$ as of day $t$. I will in this paper be considering only spot-month contracts, that is, contracts for which by day $t$ we already know some of the values for $r$ (namely $r_{\tau}$ for $\tau \leq t$ ) that will end up determining $S$. My forthcoming paper demonstrates that for futures contracts at short horizons (the spot-month, 1-month-ahead, and 2-month-ahead contracts), expression (6) appears to be an excellent approximation to the data, though Piazzesi and Swanson (2006) note potential problems with assuming that it holds for longer-horizon contracts.

Suppose that the Fed changes the target for the effective fed funds rate on calendar day $n$ of this month. Kuttner (2001) suggested that we could use the change in the spot-month contract price on day $n$ to infer how much of the change in the target interest rate caught

\footnotetext{
${ }^{1}$ Specifically, if $P_{t}$ is the price of the contract agreed to by the buyer and seller on day $t$, then $f_{t}=$ $100 \times\left(100-P_{t}\right)$.
} 
the market by surprise according to the formula

$$
\frac{N}{N-n+1}\left(f_{n}-f_{n-1}\right)
$$

I will provide a formal derivation of (7) as a special case of a more general statistical inference problem explored below, but would first like to comment on one potential drawback of (7), which is that it implies a huge reweighting of observations that come near the end of the month $(n$ near $N)$. Kuttner $(2001$, p. 529) recognized that this is a potential concern here arising from the fact that (7) abstracts from the deviation between the Federal Reserve's target for the effective fed funds rate and the actual effective rate, and as a result blows up this measurement error for observations near the end of the month. Kuttner himself avoided using (7) for the last 3 days of the month. Other researchers like Gürkaynak (2005) avoid applying it to data from the last week.

Figure 1 plots the relevant variables for December 1990, which was a particularly wild month as banks adjusted to lower reserve requirements (Anderson and Rasche, 1996). Although the Fed had lowered the target to 725 basis points on December 7 , the effective fed funds rate was trading well above this the week after Christmas, and speculators seemed to be allowing for a possibility of a big end-of-year spike up, such as the 584-basis-point increase in the effective fed funds rate that was seen in the last two days of 1985 or the 975 -basis-point spike between December 28 and December 30 of 1986 . In the event, however, the effective funds rate plunged 200 basis points on December 31, 1990.

Since the December 1990 futures contract was based on the effective rate rather than the target, speculators were watching these events closely. The futures rate was tending 
well above the new target of 725 basis points in the latter part of December, partly because the month's average would include the first week's 750-basis-point target values, partly because the effective rate had been averaging above the new target subsequently, and partly in anticipation of an end-of-year spike up. When it became clear on December 31 that the last day of the year generated a big move down rather than up, the December futures contract fell by 23 basis points on a single day. Formula (7) would call for us to multiply this number by 31 , to deduce that the interest rate surprise on this day was some 713 basis points, plausible perhaps if the market was anticipating a spike up to 1250 rather than the plunge down to 550 that actually transpired. Although this is an extreme example, it drives home the lesson that one really wants to downweight the end-of-month observations rather than blow them up in the manner suggested by the expression in (7).

In the next section I'll propose a more formal statement of this problem and its solution. A necessary first step is to document some of the properties of the deviation between the target that the Fed has in place for business day $d$ (denoted $\xi_{d}$ ) and the actual Fed funds rate. The effective fed funds rate $r_{d}$ was taken from the FRED database of the Federal Reserve Bank of St. Louis (which in turn is based on the Board of Governors release H.15), and for the target $\xi_{d}$ I've used the FRED series which comes from Thornton (2005) prior to 1994 and FOMC transcripts since. I first estimated the following regression (similar to the models in Taylor, 2001, and Sarno, Thornton, and Valente, 2005) by ordinary least squares (standard errors in parentheses):

$$
r_{d}-\xi_{d}=\underset{(0.29)}{2.45}+\underset{(0.014)}{0.300}\left(r_{d-1}-\xi_{d-1}\right)+\hat{e}_{d}
$$


This regression establishes that there is modest serial correlation in deviations from the target. Of particular interest in the next section will be the calendar variation in the variability of $\hat{e}_{d}$. Let $\omega_{j d}=1$ if day $d$ occurs on the $j$ th calendar day of the month and zero otherwise. A regression of $\hat{e}_{d}^{2}$ on $\left\{\omega_{j d}\right\}_{j=1}^{31}$ then gives the average squared residual as a function of the calendar day of the month:

$$
\hat{e}_{d}^{2}=\sum_{j=1}^{31} \hat{\beta}_{j} \omega_{j d}+\hat{v}_{d} .
$$

The estimated values $\hat{\beta}_{j}$ are plotted as a function of the calendar day $j$ in Figure 2 along with the $95 \%$ confidence intervals for each coefficient. A big outlier on January 23, 1991 (when the funds rate spiked up nearly 300 basis points on a settlement Wednesday) is enough to skew the results for day 23. Apart from this the most noticeable feature is an increased volatility of the deviation of the funds rate from the target towards the end of a month. One can represent this tendency parametrically through the following restricted regression,

$$
\hat{e}_{d}^{2}=\underset{(40)}{283}+\underset{(232)}{1746} \times 0.5^{\left(31-t_{d}\right)}+\hat{v}_{d}
$$

for $t_{d}$ the calendar day of the month associated with business day $d$. The predicted values from (9) are also plotted in Figure 2. A simple formulation based on (8) and (9) will be used to characterize the modest predictability of deviations from the target and their tendency to become more pronounced at the end of the month in the theoretical derivations in the next section. 


\section{Accounting for the volatility of spot-month futures prices.}

Suppose that market participants know that, if the Fed is going to change the target within a given month consisting of $N$ calendar days, it would do so on calendar day $n$, so that its target is a step function:

$$
\begin{array}{ll}
\xi_{t}=\xi_{0} & \text { for } t=1,2, \ldots, n-1 \\
\xi_{t}=\xi_{n} & \text { for } t=n, n+1, \ldots, N .
\end{array}
$$

The effective fed funds rate for each day is the sum of the target for that day plus the deviation from the target, denoted $u_{t}$ :

$$
r_{t}=\xi_{t}+u_{t}
$$

It follows from (5) and (6) that

$$
\begin{aligned}
f_{t} & =E_{t}\left[N^{-1} \sum_{\tau=1}^{N}\left(\xi_{\tau}+u_{\tau}\right)\right] \\
& =\left(\frac{n-1}{N}\right) \xi_{0}+\left(\frac{N-n+1}{N}\right) E_{t}\left(\xi_{n}\right)+N^{-1} \sum_{\tau=1}^{t} u_{\tau}+N^{-1} \sum_{\tau=t+1}^{N} E_{t}\left(u_{\tau}\right) .
\end{aligned}
$$

On the day before the target change, I presume that market participants had some expectation of what the target was going to be, denoted $E_{n-1}\left(\xi_{n}\right)$. The actual target would deviate from this by some magnitude $h_{n}$ :

$$
\xi_{n}=E_{n-1}\left(\xi_{n}\right)+h_{n} .
$$

If the equilibrium fed funds price is determined by risk-neutral rational speculators, the forecast error $h_{n}$ would be a martingale difference sequence that represents the content of 
the news about $\xi_{n}$ that arrived on the day of the target change itself. Similarly,

$$
\xi_{n}=E_{n-2}\left(\xi_{n}\right)+h_{n}+h_{n-1}
$$

for $h_{n-1}$ the news that arrived on day $n-1$ of the Fed's intentions on day $n$, and

$$
\xi_{n}=h_{n}+h_{n-1}+h_{n-2}+\cdots+h_{1}+E_{0}\left(\xi_{n}\right) .
$$

Under rational expectations, $\left\{h_{t}\right\}$ should be a sequence of zero-mean, serially uncorrelated variables, whose unconditional variance I denote $\sigma_{h}^{2}$. Notice that $h_{1}$ represents the information that the market receives on day 1 about the value for the target that the Fed will adopt on day $n, h_{2}$ represents the new information received on day 2 , and so on, with

$$
E_{t}\left(\xi_{n}\right)=\left\{\begin{array}{ll}
\xi_{0}\left(\xi_{n}\right)+h_{1}+h_{2}+\cdots+h_{t} & \text { for } t \leq n \\
\xi_{n} & \text { for } t>n
\end{array} .\right.
$$

Given (8) and (9), I assume that deviations follow an $A R(1)$ process with an innovation variance that increases at the end of the month,

$$
\begin{gathered}
u_{t}=\phi u_{t-1}+\varepsilon_{t} \\
E\left(\varepsilon_{t}^{2}\right)=\gamma_{0}+\gamma_{1} \delta^{(N-t)}
\end{gathered}
$$

where the empirical results suggest values of $\phi=0.30, \gamma_{0}=283, \gamma_{1}=1746$, and $\delta=0.5$. Then

$$
\begin{aligned}
\sum_{\tau=t+1}^{N} E_{t}\left(u_{\tau}\right) & =\phi u_{t}+\phi^{2} u_{t}+\cdots+\phi^{N-t} u_{t} \\
& =\frac{\phi\left(1-\phi^{N-t}\right)}{1-\phi} u_{t}
\end{aligned}
$$


Substituting (11) and (12) into (10) gives

$$
\begin{gathered}
f_{t}=\left(\frac{n-1}{N}\right) \xi_{0}+\left(\frac{N-n+1}{N}\right)\left[E_{0}\left(\xi_{n}\right)+h_{1}+h_{2}+\cdots+h_{t}\right] \\
+N^{-1} \sum_{\tau=1}^{t} u_{\tau}+N^{-1} \frac{\phi\left(1-\phi^{N-t}\right)}{1-\phi} u_{t} \quad \text { for } t \leq n \\
f_{t}=\left(\frac{n-1}{N}\right) \xi_{0}+\left(\frac{N-n+1}{N}\right) \xi_{n} \\
\quad+N^{-1} \sum_{\tau=1}^{t} u_{\tau}+N^{-1} \frac{\phi\left(1-\phi^{N-t}\right)}{1-\phi} u_{t} \text { for } t>n .
\end{gathered}
$$

From (13) we can then calculate the change in the spot-month futures rate for $t \leq n$ to be

$$
\begin{aligned}
f_{t}-f_{t-1} & =\left(\frac{N-n+1}{N}\right) h_{t}+N^{-1} \frac{\left(1-\phi^{N-t+1}\right)}{1-\phi} u_{t}-N^{-1} \frac{\phi\left(1-\phi^{N-t+1}\right)}{1-\phi} u_{t-1} \\
& =\left(\frac{N-n+1}{N}\right) h_{t}+N^{-1} \frac{\left(1-\phi^{N-t+1}\right)}{1-\phi}\left(\phi u_{t-1}+\varepsilon_{t}\right)-N^{-1} \frac{\phi\left(1-\phi^{N-t+1}\right)}{1-\phi} u_{t-1} \\
& =\left(\frac{N-n+1}{N}\right) h_{t}+N^{-1} \frac{\left(1-\phi^{N-t+1}\right)}{1-\phi} \varepsilon_{t} \quad \text { for } t \leq n,
\end{aligned}
$$

whereas for $t>n$, changes in futures prices are driven solely by the deviation of the effective fed funds rate from the target:

$$
f_{t}-f_{t-1}=N^{-1} \frac{\left(1-\phi^{N-t+1}\right)}{1-\phi} \varepsilon_{t} \quad \text { for } t>n .
$$

It follows that the variance of daily changes in the spot-month futures rate would be given by

$$
\begin{aligned}
& E\left[\left(f_{t}-f_{t-1}\right)^{2} \mid \text { target change on day } n\right] \\
= & \begin{cases}{[(N-n+1) / N]^{2} \sigma_{h}^{2}+\sigma_{\varepsilon, t}^{2}\left(1-\phi^{N-t+1}\right)^{2} /\left[N^{2}(1-\phi)^{2}\right]} & \text { for } t \leq n \\
\sigma_{\varepsilon, t}^{2}\left(1-\phi^{N-t+1}\right)^{2} /\left[N^{2}(1-\phi)^{2}\right] & \text { for } t>n\end{cases}
\end{aligned}
$$




$$
\sigma_{\varepsilon, t}^{2}=\gamma_{0}+\gamma_{1} \delta^{(N-t)}
$$

Prior to 1992, the day of a target change would often (but not always) occur the day after an FOMC meeting. Since 1994, it usually has occurred on the day of an FOMC meeting, but there are exceptions- three times in 2001 (January 3, April 18, and September 17) the Fed changed the target without a meeting, and in August and September of 2007 there was active speculation that the Fed was considering or possibly had even already implemented an intermeeting rate cut. Rather than treat the date $n$ as if always known to the econometrician, I have followed a different philosophy, which is to ask, How would the data look if it were generated by (15) but the econometrician does not condition on knowledge of the particular value of $n$ ? Suppose that the target change date (which the formula assumed was known to market participants as of the start of the month) could have occurred with equal probability on any one of the calendar days $n=1,2, \ldots, N$. If we let $\eta$ denote the unknown date of the target change, then the unconditional data would exhibit a calendar regularity in the variance that is described by

$$
\begin{aligned}
E\left(f_{t}-f_{t-1}\right)^{2} & =N^{-1} \sum_{n=1}^{N} E\left[\left(f_{t}-f_{t-1}\right)^{2} \mid \eta=n\right] \\
& =\frac{\left(1-\phi^{N-t+1}\right)^{2}}{N^{2}(1-\phi)^{2}} \sigma_{\varepsilon, t}^{2}+N^{-1} \sum_{n=t}^{N} \frac{(N-n+1)^{2}}{N^{2}} \sigma_{h}^{2} \\
& =\frac{\left(1-\phi^{N-t+1}\right)^{2}}{N^{2}(1-\phi)^{2}}\left[\gamma_{0}+\gamma_{1} \delta^{(N-t)}\right]+\sum_{\tau=1}^{N-t+1} \frac{\tau^{2}}{N^{3}} \sigma_{h}^{2} \\
& =\kappa_{1}(t)+\kappa_{2}(t) \sigma_{h}^{2}
\end{aligned}
$$

where

$$
\kappa_{1}(t)=\frac{\left(1-\phi^{N-t+1}\right)^{2}}{N^{2}(1-\phi)^{2}}\left[\gamma_{0}+\gamma_{1} \delta^{(N-t)}\right]
$$




$$
\kappa_{2}(t)=\frac{(N-t+1)(N-t+2)(2 N-2 t+3)}{6 N^{3}} .
$$

Expression (16) describes the variance of changes in the spot-month rate as the sum of two terms. The first term $\left(\kappa_{1}(t)\right)$ represents solely the contribution of deviations of the effective funds rate from the target. For days near the beginning of the month $(N-t$ large), this is essentially equal to $\gamma_{0} /(1-\phi)^{2}$ (the unconditional variance of $\left.u_{t}\right)$ divided by $N^{2}$ (since each $u_{t}$ contributes with weight $1 / N$ to the monthly average). This declines gradually during the month (since there are fewer days remaining for which the serial correlation in $u_{t}$ contributes to the variance) but then rises quickly at the end of the month due to the large value of $\gamma_{1}$, reflecting the increased volatility of deviations from target at month end. The second term $\left(\kappa_{2}(t)\right)$ represents the contribution of target changes to the volatility of the spot-month rates. This contribution declines monotonically as the day of the month $t$ increases owing to the fact that, as the month progresses, it becomes increasingly likely that the target change for the month has already occurred and there is no more uncertainty about the value of $\xi_{n}$ for that month. Added together, expression (16) implies that the variance of changes in the spot-month futures rate should decline over most of the month but then increase at the very end.

Expression (16) was derived under the assumption that at the beginning of every month, market participants are certain that there will be a target change on day $n$ of the month. If instead there is a fraction $\rho$ of months for which people anticipate a change on some day $n$ and a fraction $1-\rho$ for which they are certain there will be no change, the result would 
be that the last term in (16) would be multiplied by $\rho$,

$$
E\left(f_{t}-f_{t-1}\right)^{2}=\kappa_{1}(t)+\gamma_{2} \kappa_{2}(t),
$$

where $\gamma_{2}=\rho \sigma_{h}^{2}$.

I tested this model using daily data on fed funds futures contracts. ${ }^{2} \quad$ Figure 3 plots regression coefficients along with $95 \%$ confidence intervals from a regression of the squared change in the spot-month futures rate on the calendar date

$$
\left(f_{d}-f_{d-1}\right)^{2}=\sum_{j=1}^{31} \hat{\beta}_{j} \omega_{j d}+\hat{v}_{d}
$$

for $\omega_{j d}=1$ if day $d$ occurs on calendar day $j$ and is zero otherwise. In other words, $\hat{\beta}_{j}$ is the average squared change for observations falling on the $j$ th day of a month. These indeed exhibit a tendency to fall over most of the month but then rise at the end.

Let $t_{d}$ denote the calendar day associated with business day $d$ (in other words, if $\omega_{j d}=1$, then $t_{d}=j$ ). I then tested whether the specific function derived in (17) could account for this pattern by estimating via OLS the following relation:

$$
\left(f_{d}-f_{d-1}\right)^{2}=\kappa_{1}\left(t_{d}\right)+\underset{(3.3)}{27.9 \kappa_{2}}\left(t_{d}\right)+\hat{v}_{d}
$$

Note that all the parameters appearing in the functions $\kappa_{1}(t)$ and $\kappa_{2}(t)$ are known previously from the observed behavior of deviations of the effective fed funds rate from its target, so that

${ }^{2}$ Data for October 3, 1988 through June 30, 2006 were purchased from the Chicago Board of Trade, while data for July 3, 2006 through January 29, 2006 were downloaded from the now-defunct website spotmarketplace.com. For $d$ corresponding to the first day of the month (say the first day of February for illustration), $f_{d}-f_{d-1}$ was calculated as the change in the February contract between February 1 and the last business day in January. For all other days of the month, it was simply the change in the spot-month contract between day $d$ and the previous business day. 
only a single parameter was estimated directly from the behavior of the futures data, with this parameter having the interpretation as the variance of daily news the market receives in a typical month about the upcoming Fed target (recall equation (17):

$$
\hat{\gamma}_{2}=\hat{\rho} \hat{\sigma}_{h}^{2}=\underset{(3.3)}{27.9}
$$

Note also that (19) imposes 30 separate restrictions on the 31 parameters of the unrestricted regression (18). The $F(30,4521)=0.59$ test statistic leads to ready acceptance of the null hypothesis that this relation is indeed described by the function given in (16) with a $p$-value of 0.96 (again, treating $\kappa_{j}(t)$ as known functions). The model thus successfully accounts for the tendency of spot-month futures volatility to decline over most of the month but then increase the last few days. The actual volatility seems to increase more at the end of the month than the model predicts, though it is possible to attribute this entirely to sampling error.

\section{Inferring market expectations of target changes from spot-month futures rates.}

We are now in a position to answer the primary question of this paper, which is, What does an observed movement in the spot-month futures rate signal about market expectations about the target rate that is going to be set for this month? Let $\Lambda_{t}$ denote the information set available to market participants as of date $t$ and let $\Omega_{t}=\left\{f_{t}, f_{t-1}, \ldots\right\}$ be the information set that is going to be used by the econometrician to form an inference, where it is assumed that $\Omega_{t}$ is a subset of $\Lambda_{t}$, that the previous target $\xi_{0}$ is an element of both $\Omega_{t}$ and $\Lambda_{t}$, and 
that the date of the target change $n$ is an element of $\Lambda_{t}$ but not of $\Omega_{t}$. Our task is to use the observed data $\Omega_{t}$ to form an inference about how the market changed its assessment of $\xi_{n}$ based on information it received at $t$, that is, to form an assessment about

$$
\begin{aligned}
Y_{t} & =E\left(\xi_{n} \mid \Lambda_{t}\right)-E\left(\xi_{n} \mid \Lambda_{t-1}\right) \\
& = \begin{cases}h_{t} & \text { for } t \leq n \\
0 & \text { for } t>n .\end{cases}
\end{aligned}
$$

We can calculate the linear projection of $Y_{t}$ on $\Omega_{t}$ as follows (e.g., Hamilton, 1994, equation $[4.5 .27])$ :

$$
\hat{E}\left(Y_{t} \mid \Omega_{t}\right)=\frac{E\left[Y_{t}\left(f_{t}-f_{t-1}\right)\right]}{E\left[\left(f_{t}-f_{t-1}\right)^{2}\right]}\left(f_{t}-f_{t-1}\right) .
$$

Recalling (14), the numerator of (20) can be found from

$$
\begin{aligned}
E\left[Y_{t}\left(f_{t}-f_{t-1}\right)\right] & =N^{-1} \sum_{n=1}^{N} E\left[Y_{t}\left(f_{t}-f_{t-1}\right) \mid \eta=n\right] \\
& =N^{-1} \sum_{n=t}^{N} \rho E\left[\left(\frac{N-n+1}{N}\right) h_{t}^{2}\right] \\
& =N^{-1} \sum_{\tau=1}^{N-t+1} \frac{\tau}{N} \gamma_{2} \\
& =\frac{(N-t+1)(N-t+2)}{2 N^{2}} \gamma_{2} \\
& =\gamma_{2} \kappa_{3}(t) .
\end{aligned}
$$

Substituting (21) and (17) into (20) establishes

$$
\begin{aligned}
\hat{E}\left(Y_{t} \mid \Omega_{t}\right) & =\frac{\kappa_{3}(t) \gamma_{2}}{\kappa_{1}(t)+\kappa_{2}(t) \gamma_{2}}\left(f_{t}-f_{t-1}\right) \\
& =\kappa_{4}(t)\left(f_{t}-f_{t-1}\right)
\end{aligned}
$$


The parameters determining $\kappa_{4}(t)$ have all been estimated above from the properties of the deviations of the fed funds rate from the target and squared changes in the spot-month futures rate.

Figure 4 plots the function $\kappa_{4}(t)$ for these parameter values. To understand the intuition for this function, consider first the case in which the fed funds rate is always identically equal to the target, so that $\sigma_{\varepsilon, t}^{2}$ and $\kappa_{1}(t)$ are both zero. From (14), the expected squared change in the spot-month rate conditional on knowing that the target change will occur on day $n$ would be given by

$$
E\left[\left(f_{t}-f_{t-1}\right)^{2} \mid \eta=n, \sigma_{\varepsilon, t}^{2}=0\right]= \begin{cases}\sigma_{h}^{2}[(N-n+1) / N]^{2} & \text { for } t \leq n \\ 0 & \text { for } t>n\end{cases}
$$

while the covariance of the spot-month futures rate change with the expected target rate change would for this case be

$$
E\left[\left(f_{t}-f_{t-1}\right) Y_{t} \mid \eta=n, \sigma_{\varepsilon, t}^{2}=0\right]=\left\{\begin{array}{ll}
\sigma_{h}^{2}[(N-n+1) / N] & \text { for } t \leq n \\
0 & \text { for } t>n
\end{array} .\right.
$$

Thus if we knew both the date of the target change and that there were no targeting errors, the inference would be

$$
\hat{E}\left[h_{t} \mid \Omega_{t}, \eta=n, \sigma_{\varepsilon, t}^{2}=0\right]=\beta_{n}(t)\left(f_{t}-f_{t-1}\right)
$$

for

$$
\beta_{n}(t)= \begin{cases}N /(N-n+1) & \text { for } t \leq n \\ 0 & \text { for } t>n\end{cases}
$$


which reproduces Kuttner's (2001) formula (7) for the special case considered by Kuttner, namely $t=n$. If we don't know the date of the target change, but still impose no targeting error, we'd use the unconditional moments:

$$
\begin{gathered}
E\left[\left(f_{t}-f_{t-1}\right)^{2} \mid \sigma_{\varepsilon, t}^{2}=0\right]=N^{-1} \sum_{n=t}^{N} \sigma_{h}^{2}[(N-n+1) / N]^{2} \\
E\left[\left(f_{t}-f_{t-1}\right) Y_{t} \mid \sigma_{\varepsilon, t}^{2}=0\right]=N^{-1} \sum_{n=t}^{N} \sigma_{h}^{2}[(N-n+1) / N] \\
\hat{E}\left[h_{t} \mid \Omega_{t}, \sigma_{\varepsilon, t}^{2}=0\right]=\beta(t)\left(f_{t}-f_{t-1}\right) \\
\beta(t)=\frac{N^{-1} \sum_{n=t}^{N}[(N-n+1) / N]}{N^{-1} \sum_{n=t}^{N}[(N-n+1) / N]^{2}} .
\end{gathered}
$$

For $N$ large and $t=1$, the numerator of (24) would be approximately $(1 / 2)$ and the denominator about (1/3), so that the coefficient $\beta(1)$ would be close to 1.5 . This is bigger than Kuttner's expression (7), which equals unity at $n=1$, because a one unit increase in $h_{1}$ will increase the expected target on day $n>1$ by one unit but increase the futures rate on day $t=1$ by only $[(N-n+1) / N]<1$. Kuttner's formula assumes that, if we use the day $t=1$ change in the futures, the target change occurs on day $n=1$, whereas our formula assumes that in all probability the actual change is going to be implemented on some day $n>1$.

Going from $t$ to $t+1$, we drop $N^{-1}[(N-t+1) / N]$ from the numerator and drop the smaller magnitude $N^{-1}[(N-t+1) / N]^{2}$ from the denominator, so that the ratio (24) monotonically increases in $t$ until it finally reaches the same value as (7) on the last day of the month:

$$
\beta(N)=N
$$

In the presence of targeting errors, expression (22) adds the term $\kappa_{1}(t) / \gamma_{2}$ to the denominator of (24), so, as noted by Poole, Rasche, and Thornton (2002), the optimal inference 
in the presence of targeting errors always puts a smaller weight on $f_{t}-f_{t-1}$ than does (24). This explains why the function $\kappa_{4}(t)$ in Figure 4 begins at a value below 1.5 for $t=1$. The function $\kappa_{4}(t)$ then begins to increase monotonically in $t$ for the same reason as in (24). However, as $t$ increases, both the numerator and denominator in (24) become smaller whereas $\kappa_{1}(t) / \gamma_{2}$ is approximately constant (at least for small $t$ ). This latter effect eventually overwhelms the tendency of (22) to increase in $t$ and it begins to fall after the 20th day of the month. This decline accelerates toward the very end of the month as $\kappa_{1}(t)$ starts to spike up from the end-of-month targeting errors.

\section{Response of interest rates to changes in fed funds futures.}

We're now ready to return to the original question of how interest rates at various maturities seem to respond to the spot-month fed funds futures rate. Deviations of the funds rate from the target should have a quite negligible effect on maturities greater than 3 months since the autocorrelation implied by (8) dies out within a matter of days. We should therefore find that if we regress the change in Treasury yields on the change in the spot-month futures rate, the value of the regression coefficient should exhibit exactly the same pattern over the month as the function in Figure 4- the impact should rise gradually through the first half of the month and fall off quickly toward the end of the month.

As a first step in evaluating this conjecture, divide the calendar days of a month into $j=1,2, \ldots, 8$ octiles, and let $\psi_{j d}=1$ if business day $d$ is associated with a calendar date in the $j$ th octile of the month. For example, $\psi_{1 d}=1$ if day $d$ falls on the first through fourth 
days of a month, while $\psi_{8 d}=1$ if it falls on the 29th, 30th, or 31st. Let $i_{s, d}$ denote the yield in basis points on day $d$ for a Treasury bill or bond of constant maturity $s$ months; for example, $i_{12, d}$ would be the 1-year rate. Daily Treasury yields were taken from the St. Louis FRED database. Consider OLS estimation of

$$
i_{s, d}-i_{s, d-1}=\sum_{j=1}^{8} \alpha_{j s} \psi_{j d}\left(f_{d}-f_{d-1}\right)+u_{s d} .
$$

The OLS estimates $\hat{\alpha}_{j(t), s}$ along with $95 \%$ confidence intervals are plotted as a function of calendar day $t=1,2, \ldots, 31$ in Figure 5 for $s=12$ corresponding to a 1-year Treasury security. These indeed display very much the predicted pattern- an increase in the fed funds futures rate around the middle of the month has a slightly bigger effect on the 1-year Treasury rate than would the same move at the beginning of the month, and a much bigger effect than the same move had it occurred toward the end of the month. The same pattern holds for shorter yields (Figure 6) and longer yields (Figure 7).

According to the theory, we can capture the exact effect predicted for each calendar day by regressing the change in interest rates on the product of the change in fed funds futures with the function in (22)

$$
i_{s, d}-i_{s, d-1}=\lambda_{s} \kappa_{4}\left(t_{d}\right)\left(f_{d}-f_{d-1}\right)+u_{s d}
$$

where $t_{d}$ is the calendar day-of-the-month associated with business day $d, \lambda_{s}$ is the effect of a 1-basis-point increase in the target rate on a Treasury security of maturity $s$ months, and $u_{s d}$ results from factors influencing yields that are uncorrelated with changes in the expected target rate. Note that all the parameters governing $\kappa_{4}(t)$ having been inferred from the 
behavior of fed funds rates and futures alone. Estimates of $\lambda_{s}$ for different maturities $s$ are reported in the first column of Table 2, and the value of $\hat{\lambda}_{s} \kappa_{4}(t)$ is plotted as a function of $t$ in Figures 5-7 for the different maturities $s$.

I investigated the adequacy of (26) in a number of different ways. One obvious question is how important the function $\kappa_{4}\left(t_{d}\right)$ is for the regression, comparing (26) with a specification in which changes in futures prices have the same effect on interest rates regardless of when within the month they occur:

$$
i_{s, d}-i_{s, d-1}=c_{s}\left(f_{d}-f_{d-1}\right)+u_{s d}
$$

The specifications (26) and (27) are non-nested, but it is simple enough to generalize to a model that includes them both as special cases:

$$
i_{s, d}-i_{s, d-1}=c_{s}\left(f_{d}-f_{d-1}\right)+\lambda_{s} \kappa_{4}\left(t_{d}\right)\left(f_{d}-f_{d-1}\right)+u_{s d}
$$

If model (26) is correct, then we should be able to accept the null hypothesis that $c_{s}=0$, whereas if $(27)$ is correct, we should accept the null hypothesis that $\lambda_{s}=0$. If neither specification is correct, then we should reject both null hypotheses. The second and third columns of Table 2 report the OLS coefficient estimates and standard errors for (28). For maturities greater than 2 years, we accept the null hypothesis that $c_{s}=0$ and strongly reject the hypothesis that $\lambda_{s}=0$. For maturities less than 2 years, both hypotheses are rejected, suggesting that there is more to the response of short-term interest rates to fed funds futures than is captured by (26) alone. Even in these cases, however, the term involving $\kappa_{4}(t)$ makes by far the more important contribution statistically. I conclude that the model successfully 
captures a clear tendency in the data for the impact to vary across the month, although it seems to leave something out in the description of the response of short-term interest rates.

In the same spirit, we can nest (26) and (25):

$$
i_{s, d}-i_{s, d-1}=\sum_{j=1}^{8} \alpha_{j s} \psi_{j d}\left(f_{d}-f_{d-1}\right)+\lambda_{s} \kappa_{4}\left(t_{d}\right)\left(f_{d}-f_{d-1}\right)+u_{s d} .
$$

As reported in the last two columns of Table 2, results here are not as encouraging. In every case, we strongly reject the hypothesis that $\alpha_{1 s}=\cdots=\alpha_{8 s}=0$, meaning that for each maturity $s$ there are statistically significant deviations from the broad monthly pattern that is predicted by (26), and in every case readily accept the hypothesis that $\lambda_{s}=0$, meaning that the specific variation within octiles that is predicted by (26) is not particularly found in the data.

These last results are perhaps not too surprising given the many approximations embodied in (26), which assumed among other things that all months have $N=31$ calendar days and ignored both weekend effects and the fact that some business days convey much more important economic news than others (on this last point, see Poole and Rasche (2000) and Gürkaynak, Sack, and Swanson (2005)).

We can in fact carry that last point a step further and estimate a separate coefficient $\lambda_{j s}$ for every calendar day $j=1, . ., 31$ :

$$
i_{s, d}-i_{s, d-1}=\sum_{j=1}^{31} \lambda_{j s} \omega_{j d}\left(f_{d}-f_{d-1}\right)+u_{s d}
$$

where $\omega_{j d}=1$ if day $d$ falls on the $j$ th day of the month. Figure 8 plots the OLS estimates of $\lambda_{j s}$ as a function of the calendar day $j$ along with $95 \%$ confidence intervals and the predicted 
values for the function $\lambda_{j s}$ implied by (26) for 1-year Treasuries. Again the broad pattern seems to fit well, though again there are large deviations on some days that are well beyond what could be attributed to sampling error, and formal hypothesis tests comparing (30) with (26) (which the former formally nests as a special case) lead to overwhelming rejection, with a $p$-value less than $10^{-10}$ for each $s$. In addition to the details noted above, individual outliers are highly influential for the daily regression (30), and one would want to carefully model these non-Gaussian innovations $u_{s d}$ and GARCH effects before trying to fit the unrestricted pattern in any more detail. This and related tasks, such as trying to use information about the actual date of the target change when it is unambiguously known, using 1-month or 2-month futures contracts in place of the spot rate, and exploring the consequences of a secular change in $\sigma_{h}^{2}$ (e.g., Lang, Sack, and Whitesell (2003) and Swanson (2006)), we leave as topics for future research.

Although there is much more to be done before having a completely satisfactory understanding of these relations, I believe that the approach developed here gives us a plausible interpretation of the broad regularities found in the data and a sound basis for generalizing the Kuttner (2001) and Poole, Rasche and Thornton (2002) approaches. Although the methods involve some new uses of the data, the conclusion I draw is quite consistent with earlier researchers- changes in the fed funds target seem to be associated with quite large changes in Treasury yields, even for maturities up to ten years. 


\section{References}

Anderson, Richard G. and Robert H. Rasche (1996). "A Revised Measure of the St. Louis Adjusted Monetary Base," Federal Reserve Bank of St. Louis Review, 78, no. 2 (March/April), 3-14.

Cook, Timothy, and Thomas Hahn (1989). "The Effect of Changes in the Federal Funds

Rate Target on Market Interest Rates in the 1970s," Journal of Monetary Economics, 24, $331-351$.

Gürkaynak, Refet S. (2005) "Using Federal Funds Futures Contracts for Monetary Policy Analysis." Working paper, Federal Reserve Board.

Gürkaynak, Refet S., Brian Sack, and Eric Swanson (2005). "Do Actions Speak Louder Than Words? The Response of Asset Prices to Monetary Policy Actions and Statements." International Journal of Central Banking, 1, 55-93.

Gürkaynak, Refet S., Brian Sack, and Eric Swanson. (2007) "Market-Based Measures of Monetary Policy Expectations," Journal of Business and Economic Statistics, 25, 201-212.

Hamilton, James D. (1994). Time Series Analysis. Princeton: Princeton University Press.

Hamilton, James D. (forthcoming). "Daily Changes in Fed Funds Futures Prices," Journal of Money, Credit, and Banking.

Kuttner, Kenneth N. (2001). "Monetary Policy Surprises and Interest Rates: Evidence from the Fed Funds Futures Market." Journal of Monetary Economics, 47, 523-544. 
Lang, Joe, Brian Sack and William Whitesell (2003). "Anticipations of Monetary Policy in Financial Markets." Journal of Money, Credit, and Banking, 35(6, part 1), 889-909.

Nilsen, Jeffrey H. (1998). "Borrowed Reserves, Fed Funds Rate Targets, and the Term Structure." In Ignazio Angeloni and Riccardo Rovelli, eds., Monetary Policy and Interest Rates, Macmillan Press.

Piazzesi, Monika, and Eric Swanson (2006). "Futures Prices as Risk-Adjusted Forecasts of Monetary Policy." Working paper, University of Chicago.

Poole, William, and Robert H. Rasche (2000). "Perfecting the Market's Knowledge of Monetary Policy," Journal of Financial Services Research, 18, 255-298.

Poole, William, Robert H. Rasche, and Daniel L. Thornton (2002). "Market Anticipations of Monetary Policy Actions." Federal Reserve Bank of St. Louis Review, 84 (July/August), 65-94.

Sarno, Lucio, Daniel L. Thornton, and Giorgio Valente (2005). "Federal Funds Rate Prediction." Journal of Money, Credit, and Banking, 37, 449-471.

Swanson, Eric T. (2006). "Have Increases in Federal Reserve Transparency Improved Private Sector Interest Rate Forecasts?" Journal of Money, Credit, and Banking, 38, 791819.

Taylor, John b. (2001) "Expectations, Open Market Operations, and Changes in the Federal Funds Rate." Federal Reserve Bank of St. Louis Review, (July/August), 33-48.

Thornton, Daniel L. (2005). "A New Federal Funds Rate Target Series: September 27, 1982 - December 31, 1993." Working paper, Federal Reserve Bank of St. Louis, 
http://research.stlouisfed.org/wp/2005/2005-032.pdf. 
Table 1

Alternative estimates of the response of interest rates to changes in the fed funds target

$\begin{array}{lcccc}\text { Study } & \text { Cook-Hahn } & \text { Kuttner } & \text { Kuttner } & \text { Poole-Rasche } \\ \text { Specification } & (1) & (1) & (2)-(3) & (4)-(3) \\ \text { Sample } & 1974-79 & 1989-2000 & 1989-2000 & 1988-2000 \\ s=3 \text { months } & 0.55 * * & 0.27 * * & 0.79 * * & 0.73 * * \\ s=6 \text { months } & 0.54 * * & 0.22 * * & 0.72 * * & - \text {---- } \\ s=1 \text { year } & 0.50 * * & 0.20 * * & 0.72 * * & 0.78 * * \\ s=5 \text { years } & 0.21 * * & 0.10 * & 0.48^{* *} & ------ \\ s=10 \text { years } & 0.13 * * & 0.04 * & 0.32 * * & 0.48 * *\end{array}$

* indicates statistically significant with $\mathrm{p}$-value $<0.05 ; *$ denotes $\mathrm{p}<0.01$. 


\section{Table 2}

Regression coefficients relating change in interest rate on security with maturity $s$ to change in fed funds futures rate (OLS standard errors in parentheses) and p-values for hypothesis tests

\begin{tabular}{|c|c|c|c|c|}
\hline \multirow[b]{2}{*}{ maturity $(s)$} & \multirow{2}{*}{$\begin{array}{l}\begin{array}{l}\text { restricted } \\
\text { effect }\end{array} \\
\lambda_{s}\end{array}$} & $\begin{array}{l}\text { with constant } \\
\text { effect added }\end{array}$ & \multicolumn{2}{|c|}{$\begin{array}{l}\text { with separate octile } \\
\text { effects added }(\mathrm{p} \text {-value } \\
\left.\text { for indicated } \mathrm{H}_{0}\right)\end{array}$} \\
\hline & & $c_{s} \quad \lambda_{s}$ & $\alpha_{1 \mathrm{~s}}=\ldots=\alpha_{8 s}=0$ & $\lambda_{s}=0$ \\
\hline 3 months & $\begin{array}{l}0.658 * * \\
(0.022)\end{array}$ & $\begin{array}{cc}0.256 * * & 0.499 * * \\
(0.089) & (0.060)\end{array}$ & $(0.00)^{* *}$ & $(0.98)$ \\
\hline 6 months & $\begin{array}{l}0.706^{* *} \\
(0.021)\end{array}$ & $\begin{array}{l}0.286 * * 0.529 * * \\
(0.084) \quad(0.056)\end{array}$ & $(0.00)^{* *}$ & $(0.45)$ \\
\hline 1 year & $\begin{array}{l}0.748 * * \\
(0.023)\end{array}$ & $\begin{array}{ll}0.226^{* *} & 0.608^{* *} \\
(0.095) & (0.063)\end{array}$ & $(0.00)^{* *}$ & $(0.60)$ \\
\hline 2 years & $\begin{array}{l}0.685 * * \\
(0.029)\end{array}$ & $\begin{array}{cc}0.159 & 0.586^{* *} \\
(0.112) & (0.079)\end{array}$ & $(0.00)^{* *}$ & $(0.74)$ \\
\hline 3 years & $\begin{array}{l}0.641^{* *} \\
(0.030)\end{array}$ & $\begin{array}{cl}0.143 & 0.552^{* *} \\
(0.122) & (0.081)\end{array}$ & $(0.01)^{* *}$ & $(0.62)$ \\
\hline 10 years & $\begin{array}{l}0.426 * * \\
(0.028)\end{array}$ & $\begin{array}{cl}0.082 & 0.375^{* *} \\
(0.115) & (0.077)\end{array}$ & $(0.05)^{*}$ & $(0.45)$ \\
\hline
\end{tabular}

$*$ indicates statistically significant with $\mathrm{p}$-value $<0.05 ; * *$ denotes $\mathrm{p}<0.01$. 
Figure 1. Effective fed funds rate, target fed funds rate, and fed funds futures rate, December 1990 (in basis points).

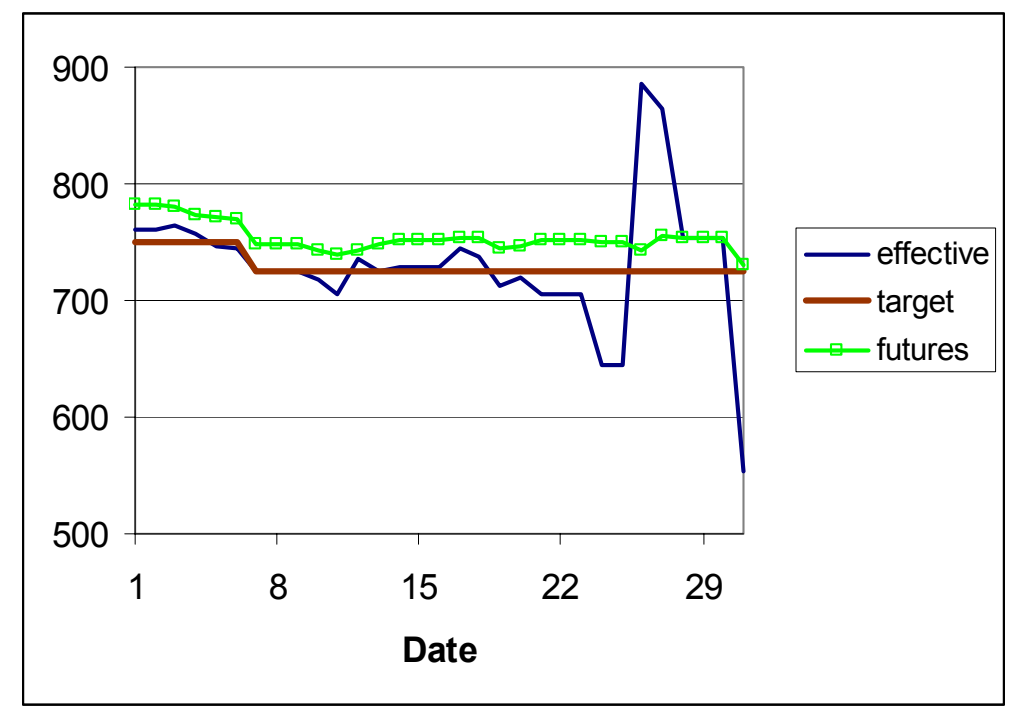


Figure 2. Average squared residual from regression of deviation of fed funds rate from target on its own lagged value, by day of the month (in basis points). Ninety-five percent confidence intervals are indicated by upper and lower box lines, and predicted values from regression (9) are indicated by the dashed curve.

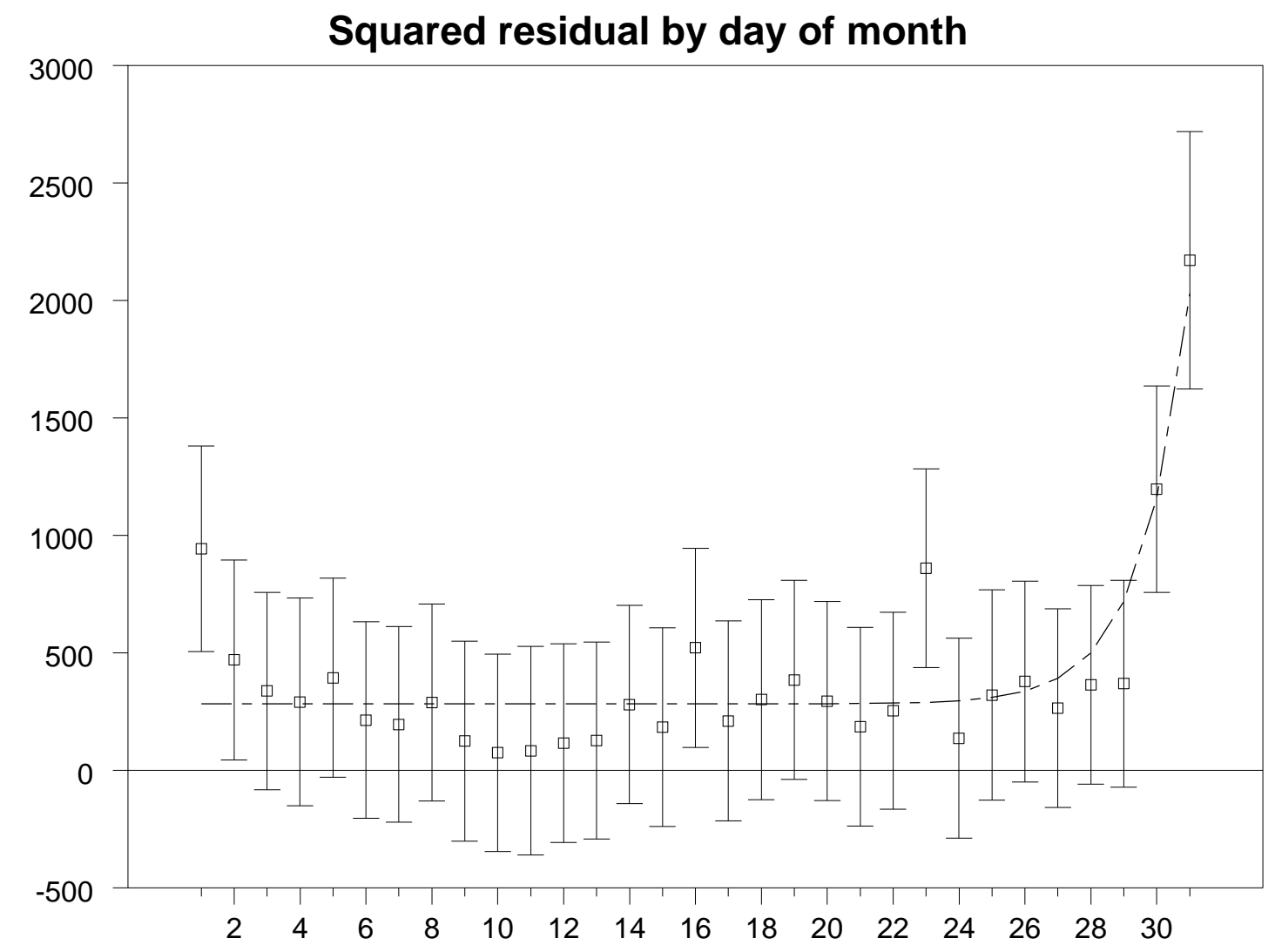


Figure 3. Average squared change in spot-month futures rate, by day of the month (in basis points). Ninety-five percent confidence intervals are indicated by upper and lower box lines, and predicted values from regression (19) are indicated by the dashed curve.

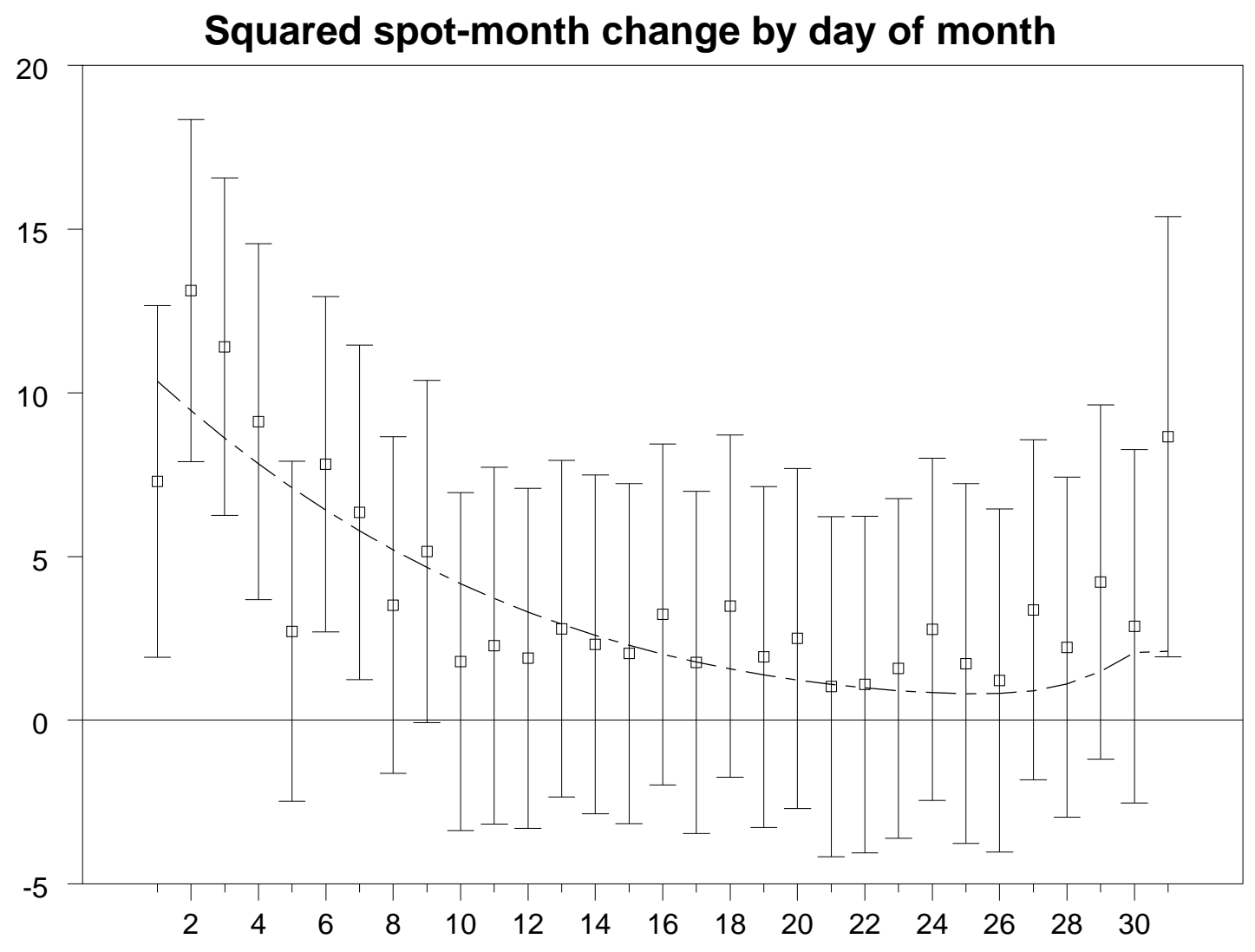


Figure 4. Plot of $\kappa_{4}(t)$ as a function of $t$.

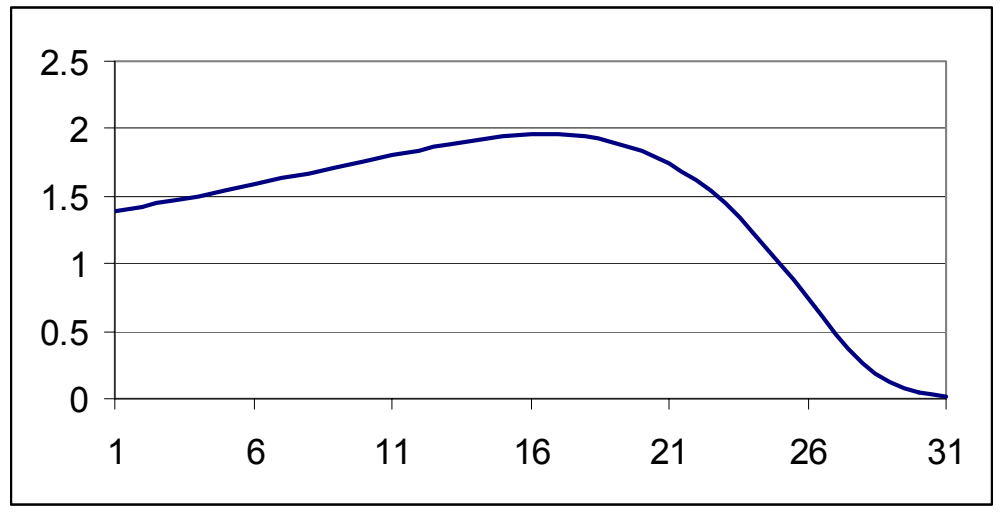


Figure 5. Coefficients and 95\% confidence intervals for OLS regression of daily change in 1-year Treasury yield on daily change in spot-month futures rate, with different coefficients for each octile based on calendar day of the month, and predicted value for coefficient for each day of the month as implied by (26).

Effect on 1-year Treasury

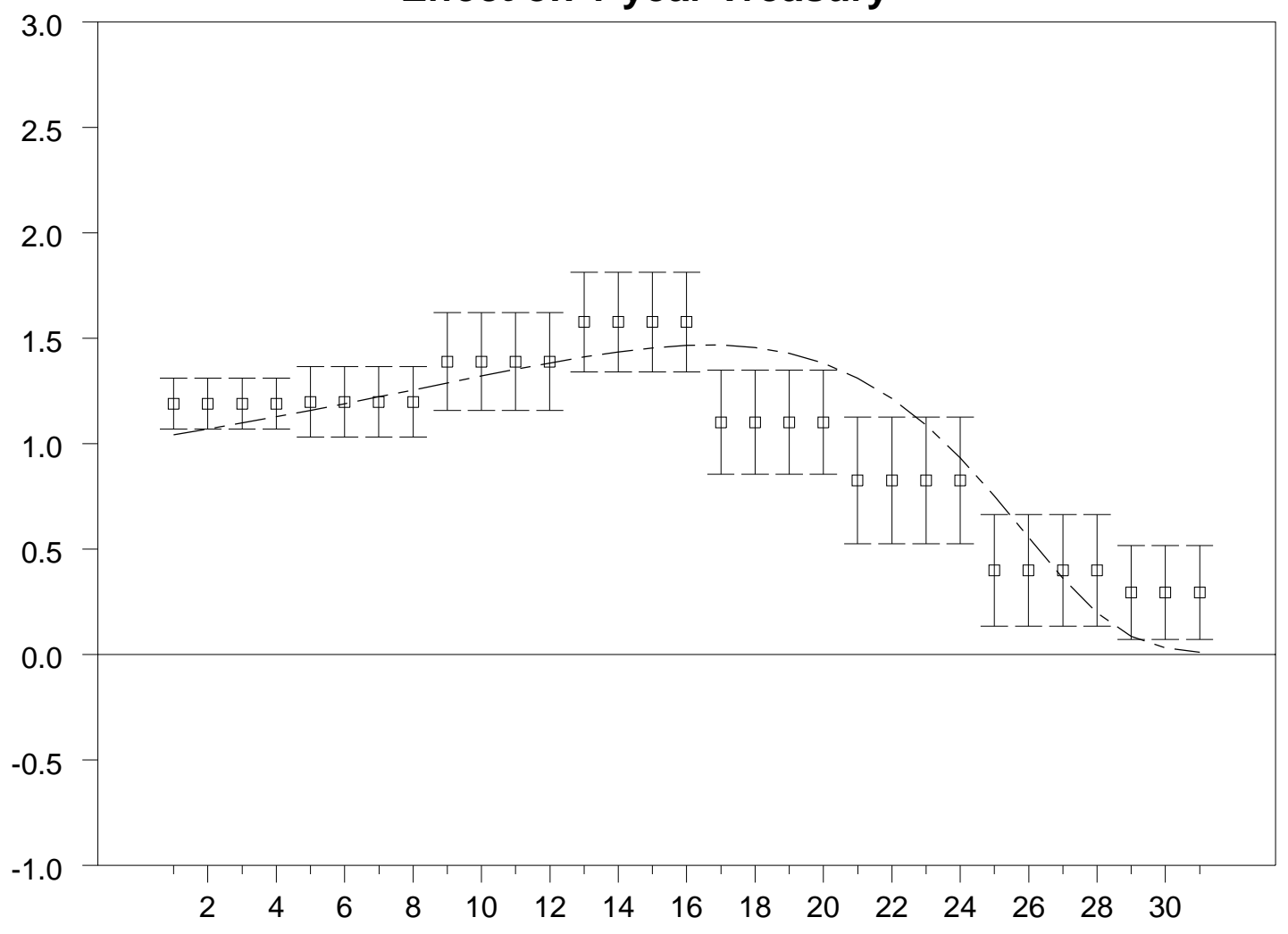


Figure 6. Coefficients and 95\% confidence intervals for OLS regression of daily change in 3- and 6-month Treasury yields on daily change in spot-month futures rate, with different coefficients for each octile based on calendar day of the month, and predicted value for coefficient for each day of the month as implied by (26).
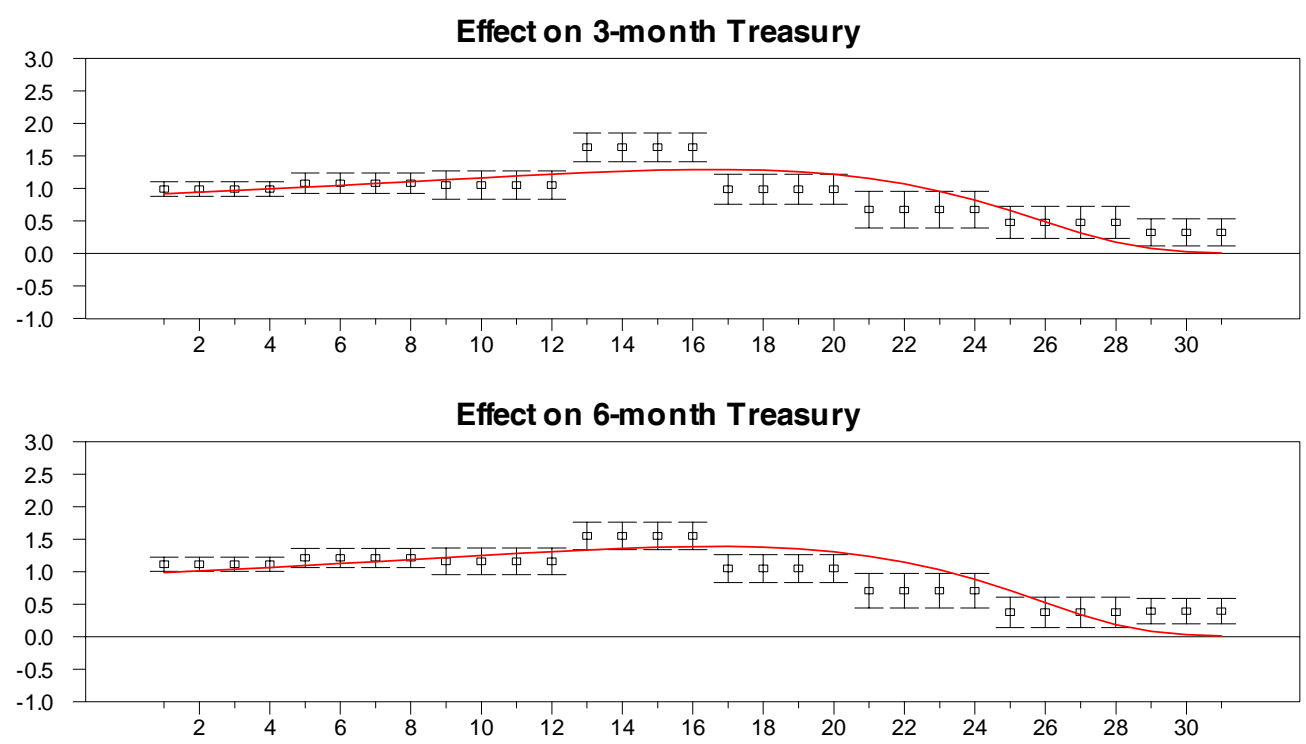
Figure 7. Coefficients and 95\% confidence intervals for OLS regression of daily change in 2-, 3-, and 10-year Treasury yields on daily change in spot-month futures rate, with different coefficients for each octile based on calendar day of the month, and predicted value for coefficient for each day of the month as implied by (26).
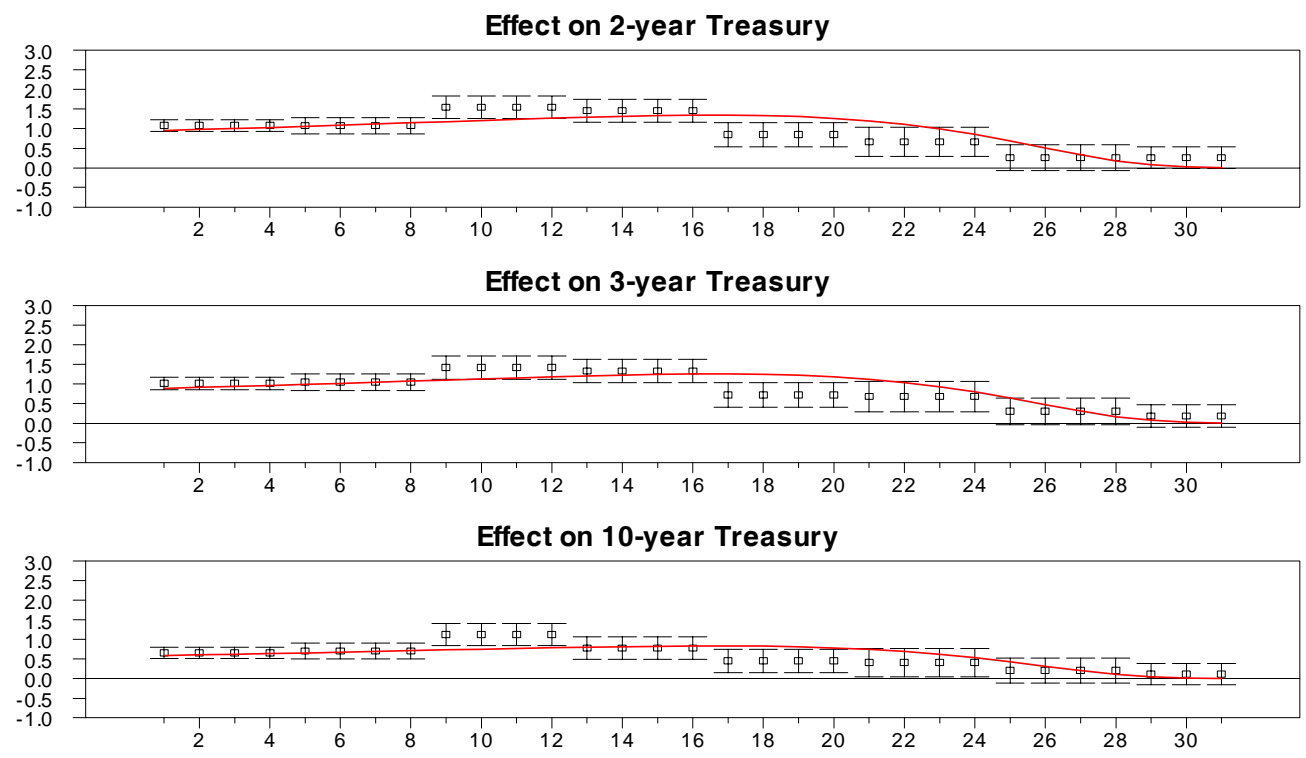
Figure 8. Coefficients and 95\% confidence intervals for OLS regression of daily change in 1-year Treasury yields on daily change in spot-month futures rate, with different coefficients for each calendar day of the month, and predicted value for coefficient for each day of the month as implied by (26).

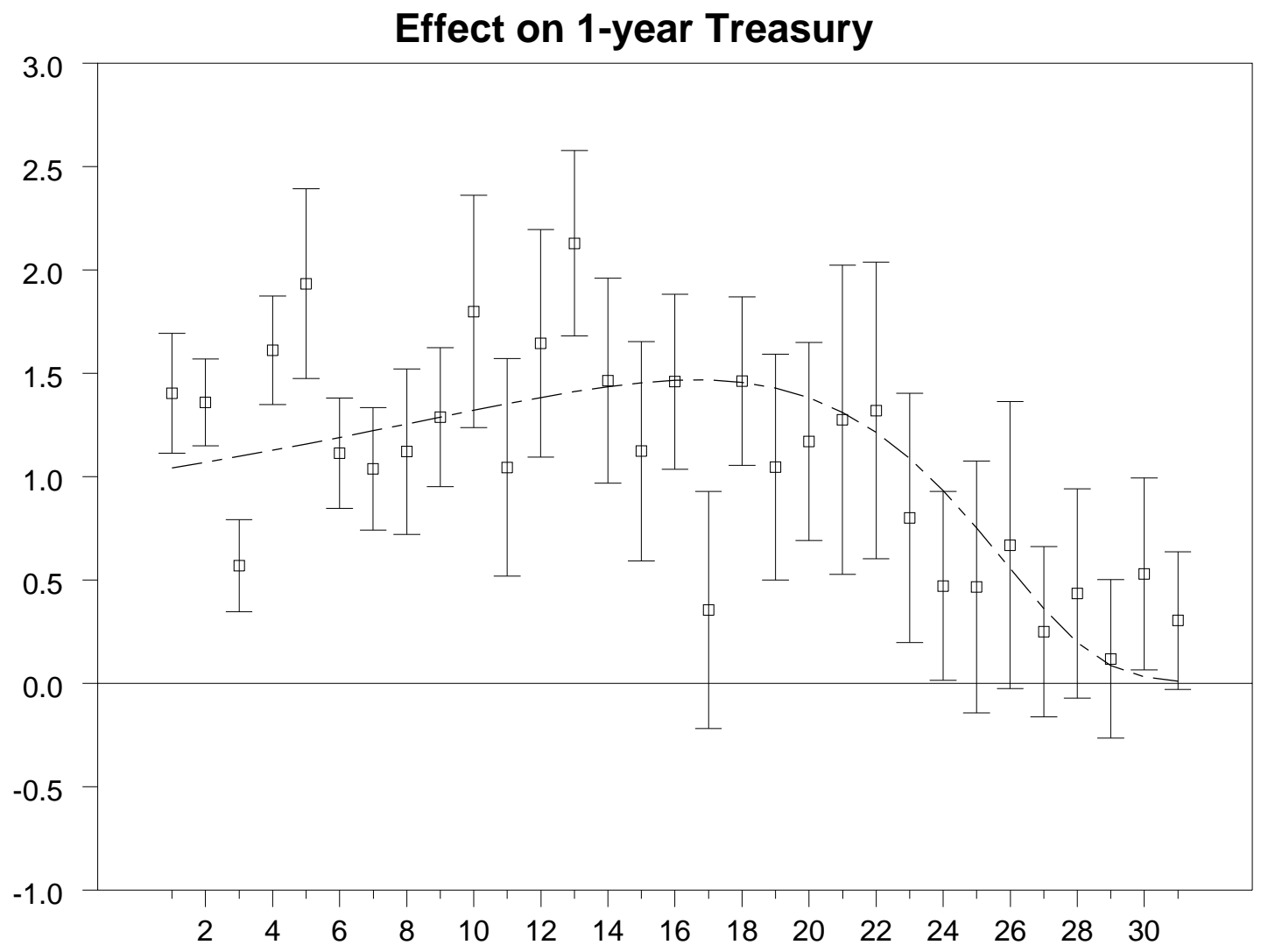

